\title{
Relationship between Sex Hormone-Binding Globulin (SHBG) and Insulin-Like Growth Factor-I (IGF-I) with Metabolic Syndrome
}

\author{
Weaam Gouda ${ }^{1}$, Lamiaa Mageed ${ }^{1}$, Esmat Ashour ${ }^{1}$, Mie Afify ${ }^{1}$, Mona Awad ${ }^{2}$, Said \\ Shalby $^{3}$, Wafaa M. Ezzat ${ }^{4}$,Yehia Shaker ${ }^{1 *}$ \\ ${ }^{1}$ Biochemistry Department, ${ }^{2}$ Department of Clinical Pathology , ${ }^{3}$ Department of \\ Complementary Medicine, ${ }^{4}$ Department of Internal Medicine, National Research \\ Center, Giza, Egypt.
}

\begin{abstract}
CLUCOSE intolerance, insulin resistance, hypertension, visceral obesity, and dyslipidemia Jare the major components of metabolic syndrome (MS). To evaluate the association between serum SHBG and IGF-1 levels and the risk of MS, Furthermore, to determine the correlations between SHBG and IGF-1 and the main components of MS. A total of 402 subjects with and without MS were enrolled in this study $(\mathrm{MS}=156$, Non-MS=246) aged $>18$ years. The age, height, weight, BMI, HC, WC, and incidence of diabetes, hypertension and dyslipidemia of all cases were recorded. The collected serum samples were used to assess lipid profile, glucose and insulin levels. The levels of LDL-cholesterol were calculated using Friedewald's formula. Insulin resistance was measured (as HOMA score). The levels of serum SHBG and IGF-1 were measured using Elisa technique. A positive relationship between SHBG and MS was detected, however no such correlation was observed concerning IGF-1. There were positive correlations between SHBG and main components of MS; with insulin, HOMA-index, TC, TG and HDL. Conversely, IGF-1 showed negative correlations. Finally, SHGB was more sensitive $(63.5 \%)$, accurate $(61.9 \%)$ than IGF-1 (51.9\%), accuracy (59\%). Our study reveals that lower SHBG is more strongly associated with metabolic syndrome and its main components that lower IGF1. SHBG could be the essential driver of these relations, conceivably reflecting its association with insulin sensitivity; however more studies are required to confirm this relationship.
\end{abstract}

Keywords: Metabolic syndrome (MS); Sex hormone-binding globulin (SHBG); Insulin like growth factor-1 (IGF-1); Insulin resistance; Visceral obesity.

\section{Introduction}

Metabolic syndrome (MS) is an important reason for mortality and morbidity in industrial nations [1]. It is described by the mixture of several disorders including insulin resistance, high blood pressure, obesity, dyslipidemia, and a proinflammatory state [2]. The metabolic syndrome is intensely related to a lifestyle characterized by an easy access to unlimited supply of high caloric, little nutrient-dense, foods and physical inactivity [3]. Psychosocial stress has also been proposed to contribute, with most metabolic constituents are more prevalent in socioeconomically deprived populations [4]. The incidence of MS associates with the worldwide prevalence of obesity and is developing at a disturbing rate, influencing over $20 \%$ of the global grown-up population [5].
Recently, in the pathogenesis of MS, nonalcoholic fatty liver disease (NAFLD) and type 2 diabetes mellitus (T2DM), further consideration has been paid to the supposed organosilanes, proteins with both endocrine or/and paracrine actions [6]. These contain most identified adipokines (mostly created by adipose tissue), myokines (principally formed by skeletal muscles) and hepatokines (mainly made by the liver) [7] It was revealed that the liver could influence the glucose and lipid metabolism by hepatokines discharged into the blood and MS appears to be accompanying with altered hepatokines creation. Insulin like growth factor-1 (IGF-1) and sex hormone-binding globulin (SHBG) are considered as the most important hepatokines.

Sex hormone-binding globulin is a serum steroid-transporting protein that is made in the

*Corresponding author e-mail: ymshaker@gmail.com 
liver. Many reports have demonstrated that decreased serum SHBG levels are associated with MS components (insulin resistance and obesity), T2DM and NAFLD [8; 9]. Insulinlike growth factor-I is a polypeptide hormone formed mostly by the liver in response to the endocrine growth hormone stimulus and controls both body composition and metabolism. There is mounting evidence suggesting that IGF-I, besides its mitogenic action, plays an active role in the regulation of protein, carbohydrate and lipid metabolism [10]. Insulin like growth factor-1 has been reported to predict the occurrence of liver steatosis in obese patients [11]. It codes for a membrane glycoprotein involved in insulin sensitivity [12]. Our study was to explore the clinical significance of SHBG and IGF-1 with MS as well as with its major components.

\section{Subjects and Methods}

\section{Subjects}

The study was performed on consecutive adults (of both sexes) who were recruited from the Medical Center of Excellence - National Research Center. This study was conducted from May 2015 to June 2016. All subjects were of the age more than 18 years old and were asked about their family history, individual health history and current medications (anti-hypertensive, oral hypoglycemic agents and lipid-lowering medicine). Subjects with any malignancy, liver cirrhosis, taking hormones, or antifungal agents, were excluded from the study. Written informed consent was obtained from each individual, and the study protocol was reviewed and approved by the Medical ethics Committee of National Research Center.

All subjects $(n=402)$ in the study were divided into MS ( $=156)$ and Non-MS $(n=246)$ groups; metabolic syndrome was diagnosed according to guidelines from the National Heart, Lung, and Blood Institute (NHLBI) and the American Heart Association (AHA) [13], metabolic syndrome was diagnosed when a patient has at least 3 of the following 5 conditions: 1) Waist circumference $\geq 102 \mathrm{~cm}$ in men or $\geq 88 \mathrm{~cm}$ in women; 2) Blood pressure $\geq 130 / 85 \mathrm{~mm} \mathrm{Hg}$ or receiving drug therapy for hypertension; 3) High-density lipoprotein (HDL) $<40 \mathrm{mg} / \mathrm{dL}$ in men or Cholesterol $<50 \mathrm{mg}$ / $\mathrm{dL}$ in women or lipid medication use; 4) Fasting glucose $\geq 100 \mathrm{mg} / \mathrm{dL}$ or receiving drug therapy for hyperglycemia; 5) Triglycerides $\geq 150 \mathrm{mg} / \mathrm{dL}$ or receiving drug therapy for hypertriglyceridemia.

\section{Measurements}

All subjects underwent the physical examination and fasting blood samples $(3 \mathrm{ml})$ were withdrawn by venipuncture for laboratory evaluation after $14 \mathrm{~h}$ of overnight fasting. The body mass index (BMI) was derived from body weight (in kilograms) divided by the square of body height in meters. Waist circumferences (WC) were measured by standard form to the nearest $0.1 \mathrm{~cm}$. Hip circumference $(\mathrm{HC})$ was measured at the maximum 2 protruding part of buttocks at the level of the greater trochanter with the patient wearing minimal clothing and feet together. Subjects were seated with legs uncrossed and were asked to refrain from talking for 10 min. Blood pressure and heart rate measurement were taken three times, with at least a 1-min interval between two consecutive readings using an automatic blood pressure monitor (using a mercury sphygmomanometer).

\section{Biochemical analyses}

Fasting plasma glucose levels and serum levels of total cholesterol, triglyceride, and HDL were measured with an enzymatic colorimetric method (Stanbio Laboratory, USA). LDL was calculated using Friedewald's formula [14]. Serum sexhormone-binding globulin (SHBG) and serum human insulin-like growth factors 1 (IGF-1) were assayed by an enzyme-linked immunosorbent assay (SHBG, IBL International GmbH, Germany and EIAab system, respectively).

\section{Statistical analysis}

Sample size calculation was done using Stats Direct statistical software version 2.8 for MS Windows, Stats Direct Ltd., Cheshire, UK. Analysis of data was done by IBM computer using SPSS (statistical program for social science version 20) (SPSS Inc., Chicago, IL, USA). Independent sample -t- test was used for comparison between the two groups. Correlations between different variables and metabolic syndrome were analyzed using Spearman correlation test.

\section{Results}

Characteristics of subjects with and without metabolic syndrome

The general characteristics of patients with and without MS are illustrated in Table 1. Significant differences were found according to age, BMI, WC, HC, waist/hip ratio, obesity (extreme obesity group only), DBP, SBP, insulin, HOMA-index, lipid profile. However, no significant differences 
were found in obesity (for overweight and obese groups).

Frequencies of SHBG and IGF-1 in subjects with and without metabolic syndrome

The frequencies of SHBG and IGF-1 in subjects with and without MS are presented in Table 2. Regarding SHBG, a significant difference occurred with the $p$ value $<0.05$ but IGF-1 showed a non-significant difference with the $\mathrm{p}$ value $>0.05$.

Correlation between ILGF-1 and metabolic indices and lipid profile

Table 3 shows the spearman's correlation coefficients between IGF-1 and metabolic indices and lipid profile. It was noticed that IGF-1 was negatively correlated with insulin, HOMA-index, TC and LDL and positively correlated with FBG, TG and HDL.
Correlation between SHGB and metabolic indices and lipid profile

Table 4 shows the spearman's correlation coefficients between SHGB and metabolic indices and lipid profile. It was found that SHGB was negatively correlated with FBG and LDL and positively correlated with insulin, HOMA-index, TC, TG and HDL.

Percent sensitivity, specificity, positive and negative predictive values (PPV, NPV) and $S H G B$ and IGF-1 accuracy in $M S$

Table 5 indicates that SHGB has more sensitivity ( $\mathrm{sn}=63.5 \%)$, accuracy $(61.9 \%)$ with significance value, $\mathrm{P}=0.020$ than IGF-1 with sensitivity ( $\mathrm{sn}=51.9 \%)$, accuracy $(59 \%)$ with P-value $=0.089$ (Fig.1\&2).

TABLE 1. Characteristics of subjects with and without metabolic syndrome.

\begin{tabular}{|c|c|c|c|c|c|}
\hline Characteristics & $\begin{array}{c}\text { Total } \\
(n=402)\end{array}$ & $\begin{array}{c}\text { None Metabolic } \\
\text { Syndrome } \\
(n=246) \\
\end{array}$ & $\begin{array}{l}\text { Metabolic } \\
\text { Syndrome } \\
(\mathrm{n}=156) \\
\end{array}$ & $P$ value & $P *$ value \\
\hline Male / Female & $171 / 231$ & $129 / 117$ & $42 / 114$ & - & - \\
\hline Age (Years) & $39.53 \pm 10.69$ & $37.61 \pm 10.66$ & $42.56 \pm 10.11$ & 0.009 & $<0.05$ \\
\hline BMI & $32.89 \pm 9.55$ & $28.26 \pm 8.44$ & $40.18 \pm 5.99$ & 0.000 & $<0.05$ \\
\hline Waist Circumference (WC) & $98.57 \pm 16.02$ & $91.24 \pm 14.88$ & $110.12 \pm 9.78$ & 0.000 & $<0.05$ \\
\hline Hip Circumference (HC) & $113.66 \pm 13.2$ & $107.83 \pm 11.78$ & $122.85 \pm 9.65$ & 0.000 & $<0.05$ \\
\hline Waist/Hip Ratio & $0.86 \pm 0.07$ & $0.84 \pm 0.07$ & $0.9 \pm 0.07$ & 0.000 & $<0.05$ \\
\hline \multicolumn{6}{|l|}{ Obesity } \\
\hline Overweight & $27(6.7 \%)$ & $21(77.8 \%)$ & $6(22.2 \%)$ & 0.096 & $<0.05$ \\
\hline Obese & $135(33.6 \%)$ & $66(48.9 \%)$ & $69(51.1 \%)$ & 0.881 & $>0.05$ \\
\hline Extreme Obesity & $102(25.4 \%)$ & $21(20.6 \%)$ & $71(79.4 \%)$ & 0.001 & $<0.05$ \\
\hline Diastolic BP (mmHg) & $121.17 \pm 15.17$ & $114.27 \pm 11.76$ & $132.06 \pm 13.53$ & 0.000 & $<0.05$ \\
\hline Systolic BP(mmHg) & $79.76 \pm 12.05$ & $75.3 \pm 9.73$ & $86.79 \pm 12.08$ & 0.000 & $<0.05$ \\
\hline $\mathrm{FBG}(\mathrm{mmol} / \mathrm{l})$ & $27.19 \pm 43.71$ & $24.6 \pm 36.58$ & $31.26 \pm 53.2$ & 0.003 & $<0.05$ \\
\hline Insulin (mIU/ml) & $8.87 \pm 4.35$ & $7.92 \pm 3.48$ & $10.37 \pm 5.14$ & 0.002 & $<\mathbf{0 . 0 5}$ \\
\hline HOMA-index & $2.05 \pm 1.18$ & $1.68 \pm 0.77$ & $2.63 \pm 1.45$ & 0.000 & $<0.05$ \\
\hline $\mathrm{TC}(\mathrm{mg} / \mathrm{dl})$ & $236.32 \pm 64.05$ & $212.91 \pm 58.98$ & $273.23 \pm 53.88$ & 0.000 & $<0.05$ \\
\hline $\mathrm{TG}(\mathrm{mg} / \mathrm{dl})$ & $179.27 \pm 78.31$ & $144.18 \pm 69.93$ & $234.61 \pm 55.88$ & 0.000 & $<0.05$ \\
\hline HDL (mg/dl) & $56.58 \pm 21.9$ & $65.24 \pm 22.61$ & $42.91 \pm 11.29$ & 0.000 & $<0.05$ \\
\hline LDL (mg/dl) & $143.89 \pm 66.01$ & $118.83 \pm 60.42$ & $183.41 \pm 54.43$ & 0.000 & $<0.05$ \\
\hline
\end{tabular}

BMI: Body mass index; TC: Total cholesterol; TG: Triglyceride; HDL: High-density lipoprotein; LDL: Low-density lipoprotein; FPG: Fasting plasma glucose.

Numeric variables are described by mean $\pm \mathrm{SD}$, and categorical data are expressed as number $(\%)$

$\mathrm{P}$ value for comparison between total subjects, MS and Non-MS groups.

$\mathrm{P}^{*}$ value for comparison between the MS and Non-MS groups.

$P$ value $<0.05$ was considered as statistically significant. 
TABLE 2. Frequencies of SHBG and IGF-1 in subjects with and without metabolic syndrome.

\begin{tabular}{|c|c|c|c|c|c|}
\hline Characteristics & $\begin{array}{c}\text { Total } \\
(\mathrm{n}=\mathbf{4 0 2})\end{array}$ & $\begin{array}{l}\text { None Metabolic Syndrome } \\
\qquad(\mathrm{n}=246)\end{array}$ & $\begin{array}{c}\text { Metabolic Syndrome } \\
\qquad(\mathrm{n}=156)\end{array}$ & P value & $\mathbf{P} *$ value \\
\hline ILGF1 (Pg/ml) & $6.75 \pm 1.59$ & $6.92 \pm 1.63$ & $6.49 \pm 1.49$ & 0.130 & $>0.05$ \\
\hline SHGB (nmol/L) & $3.37 \pm 1.35$ & $3.52 \pm 1.28$ & $3.13 \pm 1.43$ & 0.020 & $<0.05$ \\
\hline
\end{tabular}

SHBG: Sex-hormone-binding globulin; IGF-1: Human insulin-like growth factors 1.

Data are presented as mean \pm SD.

$\mathrm{P}$ value for comparison between total subjects, MS and Non-MS groups.

$\mathrm{P}^{*}$ value for comparison between the MS and Non-MS groups.

$\mathrm{P}$ value $<0.05$ was considered as statistically significant.

\section{Discussion}

Metabolic syndrome is considered as one of the main public health problems of the $21^{\text {th }}$ century. In the current study, we found significant differences between metabolic and non-metabolic syndrome groups according to BMI; WC; HC; SBP; DBP; FBG; HOMAindex; and lipids; which are the main components of the metabolic syndrome. Our finding could be explained as MS is a group of risk factors; containing increased TG levels, decreased HDL, raised central abdominal obesity, increased FBS, hyperinsulinemia, and/ or high BP [15].

Growth hormone $(\mathrm{GH})$ is the main regulator of postnatal growth and also controls both body composition and metabolism. The growth promoting the action of $\mathrm{GH}$ is mainly mediated by IGF-I, a component of the insulin-like growth factor system [16].
The mechanisms underlying the association between IGF-I levels and MS are still largely unknown. The insulin-like activity of IGF-I may account for a positive effect on insulin resistance which is closely associated with metabolic syndrome [17]. This may be due to resemblances between insulin and IGF-I indicate the probability of IGF-I involvement in the phenotypic expression of this disorder [18]. The increased insulin levels can induce a down-regulation of IGF-I secretion by the liver and other tissues, as a compensatory homeostatic mechanism, caused most likely through a differential variation of IGF-I production. This could be responsible for the increment levels of IGF-I indicated in accordance with states of IR, as the MS [19].

On the contrary, the present study suggested that serum IGF-I level was not significantly associated with MS. This could be explained by the greater incidence of IR and MS in adult population compared with younger individuals

TABLE 3. Correlation between ILGF-1 and metabolic indices and lipid profile.

\begin{tabular}{|c|c|c|}
\hline Variables & Correlation Coefficient & P value \\
\hline FBG & 0.411 & 0.002 \\
\hline Insulin & -0.018 & 0.920 \\
\hline HOMA-index & -0.008 & 0.965 \\
\hline $\mathrm{TC}$ & -0.189 & 0.286 \\
\hline TG & 0.008 & 0.966 \\
\hline HDL & 0.083 & 0.64 \\
\hline LDL & -0.228 & 0.194 \\
\hline
\end{tabular}

TABLE 4. Correlation between SHGB and metabolic indices and lipid profile.

\begin{tabular}{ccc}
\hline Variables & Correlation Coefficient & P value \\
\hline FBG & -0.116 & 0.513 \\
Insulin & 0.220 & 0.21 \\
HOMA-index & 0.277 & $\mathbf{0 . 0 4 5}$ \\
TC & 0.084 & 0.636 \\
TG & 0.255 & 0.146 \\
HDL & 0.068 & 0.704 \\
LDL & -0.009 & 0.961 \\
\hline
\end{tabular}


TABLE 5. Percent sensitivity, Specificity, PPV, NPV and accuracy of SHGB and IGF-1 in Metabolic Syndrome.

\begin{tabular}{lccccccccc}
\hline $\begin{array}{c}\text { Area } \\
\text { Parameter under the } \\
\text { curve }\end{array}$ & $\begin{array}{c}\text { Cutoff } \\
\text { value }\end{array}$ & Sensitivity \% & Specificity \% & PPV & NPV & $\begin{array}{c}\text { Test } \\
\text { Accuracy }\end{array}$ & 95\% CI & P value \\
\hline SHGB & 0.620 & 2.936 & $63.5 \%$ & $61.0 \%$ & $50.8 \%$ & $72.5 \%$ & $61.9 \%$ & 0.518 to 0.721 & $\mathbf{0 . 0 2 0}$ \\
ILGF1 & 0.587 & 6.150 & $51.9 \%$ & $63.4 \%$ & $47.4 \% 67.5 \%$ & $59.0 \%$ & 0.488 to 0.687 & 0.089 \\
\hline
\end{tabular}

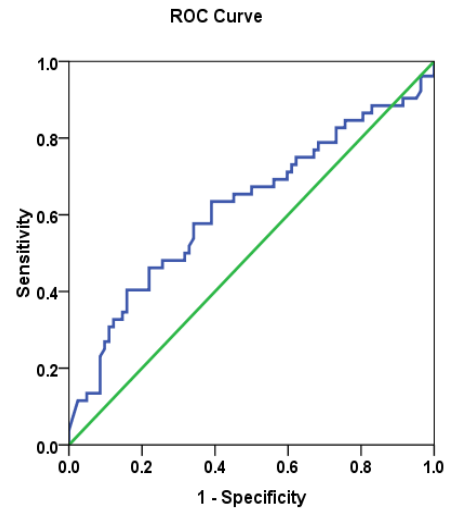

Fig.1. ROC Curve for SHGB in Metabolic Syndrome .

might also be attributable, nevertheless partially, to the decay concentrations of serum and tissue IGF-I with progressing age [20]. Reduced IGF-I levels are independently associated with glucose intolerance, diabetes, abdominal obesity [21; 22] and atherogenic dyslipidemia [23]. There are interesting discrepancies for understanding the physiological relevance of the reduced IGF-I axis in aging. Several studies have suggested that reduced IGF-I activity promotes longevity [24], and a significant amount of evidence has been accumulated indicating that IGF-I might play a role in several pathological conditions commonly seen during aging. These pathologies are associated with oxidative tissular damage. This effect can be an additional mechanism to explain the antioxidant activity displayed by this hormone in conditions of "IGF-I deficiency" [25]. The mechanisms responsible for the effects of IGF-I are not fully understood that require further investigation [26].

Our data reported that serum levels of SHBG were decreased in MS group as compared to non- MS. Our finding was in agreement with $\mathrm{Li}$ et al. [19] and Liao et al. [20]; who found that the serum concentration of SHBG was associated with MS. Our data could be explained on the basis that the crucial abnormality detected in MS seems to be

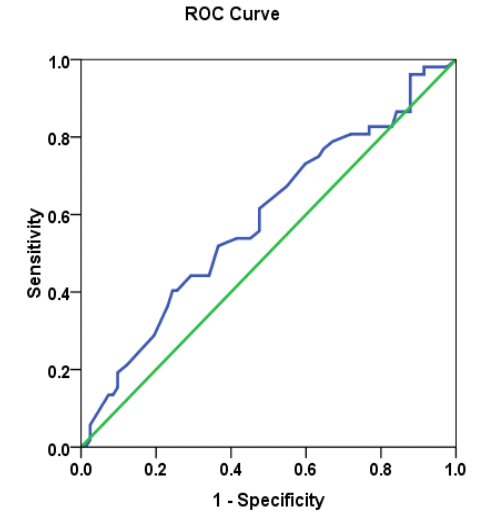

Fig. 2. ROC Curve for ILGF-1 in Metabolic Syndrome

IR in peripheral tissues. Since insulin is a powerful suppressor of SHBG generation in the liver, it is conceivable that reduced levels of SHBG might be an initial indicator for MS. Likewise, Heald et al. [27] in an investigation examining AfroCaribbean, European and Pakistani populaces and Chubb et al. [28] in a population-based study, recommended that $\mathrm{SHBG}$ is a potential marker for MS. Recently, Caldas et al., [29] described that a rise of one unit in insulin concentrations lead to a drop of 0.25 units in SHBG concentrations, in a non-interventional study examining 80 subjects with MS.

A powerful relationship was observed between lipids and SHBG, making SHBG to be expected as a valuable predictor for the metabolic syndrome distinct by the National Cholesterol Education Program Adult Treatment Panel [30]. This description excludes insulin resistance as a risk factor for this disorder, and along these lines, it has a tendency to be more weighted toward lipid constituents and abdominal obesity as compared to the WHO explanation of the metabolic syndrome. Since IGF-1 does not have a relationship with either insulin or insulin resistance, and its relation with SHBG is stronger than for lipids, IGF-1 is most likely less significant in expecting the MS well-defined by the Program of National

Egypt. J. Chem. 60, No.5 (2017) 
Cholesterol Education.

\section{Conclusion}

In conclusion, serum SHBG level inversely correlates with the prevalence of metabolic syndrome, but not serum level of IGF-1. Metabolic Syndrome is increasing in emerging countries, making this disease a public health problem. Although, the exact mechanisms is linking MS disease remain only partly known. We recommended that further research is warranted for the better understanding of the pathophysiology of MS and for better identifying potential therapeutic targets in this ever growing disease.

\section{Declaration of interest}

The authors declare that there is no conflict of interest that could be perceived as prejudicing the impartiality of the research reported.

\section{Funding}

This study was supported by project grants from the National Research Center (Project no. 10010205).

\section{References}

1. Simons, L.A., Simons, J., Friedlander, Y., McCallum, J., Is prediction of cardiovascular disease and all-cause mortality genuinely driven by the metabolic syndrome, and independently from its component variables? The Dubbo study. Heart Lung Circ. 20, 214-219 (2011).

2. Reaven, G., Metabolic syndrome: pathophysiology and implications for management of cardiovascular disease. Circulation 106, 286-288 (2002).

3. Pimenta AM, Toledo E, Rodriguez-Diez MC et al., Dietary indexes, food patterns and incidence of metabolic syndrome in a Mediterranean cohort: The SUN project. Clin Nutr. 34, 508-514 (2015).

4. HanT and Lean M., A clinical perspective of obesity, metabolic syndrome and cardiovascular disease. Journal of the Royal Society of Medicine Cardiovascular Disease. 5, 1-13 (2016).

5. Onat, A., Metabolic syndrome: nature, therapeutic solutions and options. Expert Opin. Pharmacother. 12, 1887-1900 (2011).

6. Asrih M1, Jornayvaz FR2. Metabolic syndrome and nonalcoholic fatty liver disease: Is insulin resistance the link?Mol Cell Endocrinol. 2015 Dec
15; 418Pt 1:55-65. doi: 10.1016/j.mce.2015.02.018. Epub 2015 Feb 24 (2015).

7. Stefan N, Kantartzis K, Machann J, Schick F, Thamer C, Rittig K, Balletshofer B, Machicao F, Fritsche A, Häring HU. Identification and characterization of metabolically benign obesity in humans. Arch Intern Med. 168,1609-1616 (2008).

8. Ding, E.L., Song, Y., Manson, J.E. Sex hormonebinding globulin and risk of type 2 diabetes in women and men.New England Journal of Medicine, 361, 1152-1163 (2009) .

9. Shin, J.Y., Kim, S.K., Lee, M.Y. Serum sex hormone-binding globulin levels are independently associated with nonalcoholic fatty liver disease in people with type 2 diabetes. Diabetes Research and Clinical Practice, 94, 156-162 (2011).

10. Inzaghi E, Cianfarani S \& Nobili V. Insulin-like growth factors (IGF-I and -II): new actors in the development of non-alcoholic fatty liver disease. Expert Rev. Endocrinol. Metab. 9(3), 193-195 (2014).

11. Alisi A, Feldstein AE, Villani A, Pediatric nonalcoholic fatty liver disease: a multidisciplinary approach. Nat RevGastroenterol Hepatol 9(3),15261 (2012).

12. Colak Y, Senates E, Ozturk O, Serum concentrations of human insulin-like growth factor-1 and levels of insulin-like growth factor-binding protein-5 in patients with nonalcoholic fatty liver disease: association with liver histology. Eur J Gastroenterol Hepatol 24(3),255-61 (2012).

13. Alberti KG, Eckel RH, Grundy SM, Zimmet PZ, Cleeman JI, Donato KA, Harmonizing the metabolic syndrome: a joint interim statement of the International Diabetes Federation Task Force on Epidemiology and Prevention; National Heart, Lung, and Blood Institute; American Heart Association; World Heart Federation; International Atherosclerosis Society; and International Association for the Study of Obesity. Circulation. 120 (16), 1640-5 (2009).

14. Friedewald W.T., Levy R.I., Fredrickson D.S. Estimation of the concentration of low density lipoprotein cholesterol in plasma, without use of the preparative ultracentrifuge, Clin. Chem. 18 499-502 (1972) .

15. Alberti KG, Zimmet P, Shaw J; IDF Epidemiology Task Force Consensus Group. The metabolic syndrome-a new worldwide definition. Lancet

Egypt. J. Chem. 60, No.5 (2017) 
366,1059-1062 (2005).

16. Ichikawa T, Nakao K, Hamasaki K, et al.Role of growth hormone, insulin-likegrowth factor 1 and insulin-like growth factor-binding protein 3 in development of non-alcoholic fatty liver disease. Hepatol Int. 1(2), 287-94 (2007).

17. Yakar S, Liu JL, Fernandez AM, et al. Liverspecific igf-1 gene deletion leads to muscle insulin insensitivity. Diabetes; 50(5),1110-1118 (2001).

18. Akanji AO, Smith RJ: The insulin-like growth factor system, metabolic syndrome, and cardiovascular disease risk. Metab Syndr Relat Disord, 10(1)3-13 (2012).

19. Li C, Ford ES, Li B, Giles WH, Liu S. Association of testosterone and sex hormone-binding globulin with metabolic syndrome and insulin resistance in men. Diabetes Care 33,1618-1624 (2010).

20. Liao CH, Huang CY, Li HY, Yu HJ, Chiang HS and Liu CK. Testosterone and sex hormonebinding globulin have significant association with metabolic syndrome in Taiwanese men. The Aging Male, 15(1), 1-6(2012).

21. Garcia-Fernandez M, Delgado G, Puche JE, Gonzalez-Baron S, Castilla Cortazar I: Low doses of insulin-like growth factor I improve insulin resistance, lipid metabolism, and oxidative damage in aging rats Endocrinology 149(5), 2433-2442 (2008).

22. Conti E, Andreotti F, Sestito A, Riccardi P, Menini E, Crea F, Maseri A, Lanza GA: Reduced levels of insulin-like growth factor-1 in patients with angina pectoris, positive exercise stress test, and angiographically norma epicardial coronary arteries. Am J Cardiol 89(8),973-975(2002).

23. Gomez JM, Maravall FJ, Gomez N, Navarro MA, Casamitjana R, Soler J: Interactions between serum leptin, the insulin-like growth factor-I system, and sex, age, anthropometric and body composition variables in a healthy population randomly selected. Clin Endocrinol 58(2),213-219 (2003).
24. Hypponen E, Boucher BJ, Berry DJ \& Power C: 25-Hydroxyvitamin D, IGF-1, and metabolic syndrome at 45 years of age: a crosssectional study in the 1958 British Birth Cohort. Diabetes 57, 298 305 (2008).

25. Andreassen M, Raymond I, Kistorp C, Hildebrandt P, Faber J \& Kristensen LO: IGF1 as predictor of all-cause mortality and cardiovascular disease in an elderly population. European Journal of Endocrinology 160, 25-31 (2009).

26. van Bunderen, Mirjam M, van Schoor N, Dorly Deeg J, Paul Lips P and Madeleine L: Serum IGF1, metabolic syndrome, and incident cardiovascular disease in older people: a population-based study Christa C, European Journal of Endocrinology 168, 393-401(2013).

27. Heald AH, Anderson SG, Ivison F, et al. Low sex hormone binding globulin is a potential marker for the metabolic syndrome in different ethnic groups. Exp Clin Endocrinol Diabetes. 113 (9),5228(2005).

28. Chubb SA, Hyde Z, Almeida OP, Lower sex hormone-binding globulin is more strongly associated with metabolic syndrome than lower total testosterone in older men: The health in men study. Eur J Endocrinol.158(6),785-92 (2008).

29. Caldas ADA, Porto AL, Motta LDC, Casulari LA. Relaçao entre insulina e hipogonadismo em homens com sndrome metablica [Relationship between insulin and hypogonadism in men with metabolic syndrome]. Arq Bras Endocrinol Metabol. 53(8),1005-11(2009).

30. National Cholesterol Education Program Executive Summary of the Third Report of the National Cholesterol Education Program (NCEP) Expert Panel on Detection, Evaluation, and Treatment of High Blood Cholesterol in Adults (Adult Treatment Panel III). JAMA 285,2486-2497(2001).

(Received 19/8/2017; accepted 25/9/2017) 


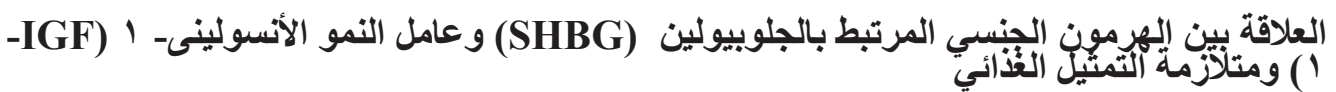

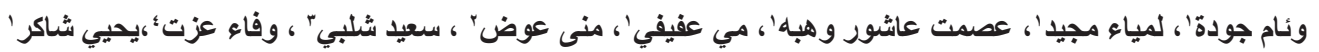

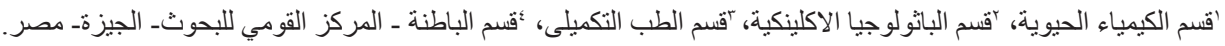

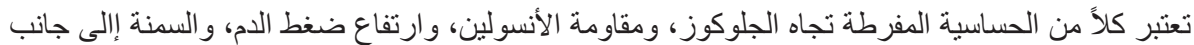

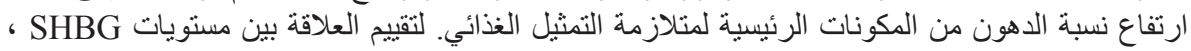

I-IGF IIGF ، SHBG

تمت الدراسة على ب بـ؛ حالة من الأشخاص الذين يعانون و الذين لايعانون من متلازمة التمثيل الغذائي

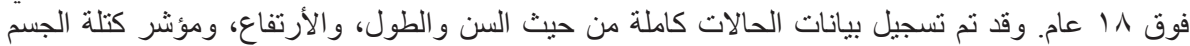

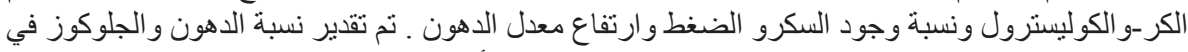

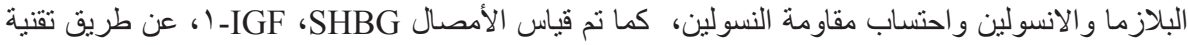

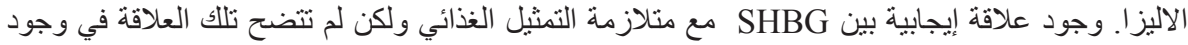

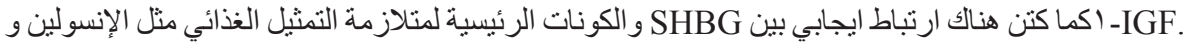
HOMA

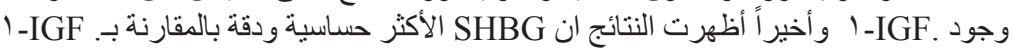

أظهرت هذه الدر اسة عن الارتباط الوثيق بين مصل SHBG و و متلازمة التمثيل الغذائي ومكوناتها الأساسية

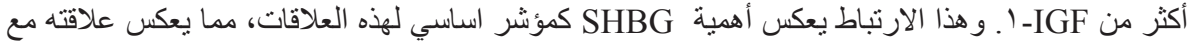
حساسية الأنسولين ولكن هناك حاجة لمزيد من الدراسات لتاكيد هذه العلافة. 